Forthcoming in Religious Studies

\title{
Faith as Extended Knowledge
}

Kegan J Shaw

University of Edinburgh

\begin{abstract}
:
You don't know that $p$ unless it's on account of your cognitive abilities that you believe truly that $p$. Virtue epistemologists think there's some such ability constraint on knowledge. This looks to be in considerable tension, though, with putative faithbased knowledge. For at least on a popular Christian conception, when you believe something truly on the basis of faith this isn't because of anything you're naturally competent to do. Rather faith-based beliefs are entirely a product of divine agency. Appearances to the contrary, I argue in this paper that there's no deep tension between faith-based knowledge and virtue epistemology. Not if we learn to conceive of faith as a kind of extended knowledge.
\end{abstract}




\section{INTRODUCTION}

You can't know that $p$ unless it's on account of you that you believe truly that $p$. That is to say, unless it's on account of your cognitive abilities. It's commonly held that there's some such ability constraint on knowledge-at least among proponents of virtue epistemology. ${ }^{1}$ It entails that you can't know something you haven't abilities to form true belief about.

This seems in considerable tension, however, with faith-based knowledgeparticularly as that's conceived in Alvin Plantinga's well-known work Warranted Christian Belief (2000). For while there he maintains that faith is a means of knowing religious subject matter, he's also candid that faith-based belief is produced in one by the Holy Spirit in a way that can seem to openly flout the ability constraint on knowledge. For it can seem that it's precisely because human beings don't have the ability to reliability form such religious beliefs on their own that faith-based belief is produced in the way Plantinga describes.

We can express this problem for Plantinga's view in terms of a new argument for agnosticism about religious faith from the ability constraint on knowledge:

1) If you know that $p$ then you truly believe that $p$ on account of your cognitive abilities. (Ability Constraint)

2) Cases of faith-based belief are not cases in which you form true beliefs on account of your cognitive abilities. (No Ability)

3) Therefore, you don't know anything you believe on the basis of faith. (Agnosticism)

This argument seems to make trouble for any virtue-theoretic religious epistemology that would seek to explain faith-based knowledge on Plantinga's model. Let's call the

\footnotetext{
${ }^{1}$ And so Ernest Sosa (2016, p. 19) writes that knowledge "amounts to belief that is apt, belief that is an apt by manifesting the relevant competence of the believer in attaining the truth" (my emphasis). John Greco too conceives of knowledge as a kind of "success from ability". He writes $(2010$, p.71) that " $S$ knows that $p$ if and only if $S$ believes the truth (with respect to $p$ ) because $S$ 's belief that $p$ is produced by intellectual ability." And Duncan Pritchard (2010, p. 134) writes that "[a] true belief, no matter what else of epistemic relevance can be offered in its favor [...] will not count as knowledge if it is not the product of cognitive ability."
} 
person for whom the above argument poses a threat the Plantingian virtue religious epistemologist. ${ }^{2}$ Since this person won't dispute the ability constraint, in order to avoid agnosticism about faith-based belief she'll have to explain how it is that in these cases one truly believes some religious proposition on account of her own cognitive abilities, despite appearances to the contrary.

$\mathrm{I}$ argue in this paper that the Plantingian virtue religious epistemologist can make sense of this only by conceiving of faith-based knowledge as the product of an extended cognitive ability (which we'll clarify below), rendering faith-based knowledge a kind of extended knowledge. Premise 2 (No Ability) in the above argument is false since it isn't the case that when you believe something truly on the basis of faith you don't get it right on account of your cognitive abilities. On the contrary it's on account of an extended cognitive ability that you believe truly what you do in such cases.

In the first section of the paper I motivate the above problem for the Plantingian virtue religious epistemologist, before considering and rejecting what might be thought to be an easy solution to the problem. I'll then be well-positioned to advance my positive proposal: that in order to avoid agnosticism about faith-based belief the virtue theorist at issue should conceive of faith-based knowledge as a kind of extended knowledge, by virtue of being produced by an extended cognitive ability. ${ }^{3}$ This I do in section two, bringing to bear recent developments in cognitive science for articulating how the belief-producing process at issue in faith-based belief might constitute a rather abnormal cognitive process, but a cognitive process all the same-one that is both extended and

\footnotetext{
${ }^{2}$ I should highlight up front that No Ability effectively assumes that you know the elements of the basic Christian story only by believing them on the basis of the mechanism the Plantinga describes (and which I'll articulate below). But the threat posed here to religious faith will be mitigated if Plantinga is wrong about how faith-based belief is standardly produced in subjects, or if there are other means of properly knowing the basic elements of the Christian story. I should emphasize that the problem for faith-based knowledge at issue here is generated only on Plantinga's particular Calvinist-inspired conception of faithbased belief. If you conceive of faith otherwise then you may have no need for the conception of faithbased knowledge as extended knowledge that I motivate through the course of the paper. Thanks to a referee for encouraging me to state this clearly.

${ }^{3}$ In fact, what I'm arguing for on behalf of the virtue reliabilist in connection with faith-based belief is what Orestis Palermos (2014, p. 1946-1947) has argued for in connection with knowledge from instruments. With respect to more "advanced cases of knowledge where one's believing the truth is the product of the operation of epistemic artifacts such as telescopes, microscopes, tactile visual substitution systems and so on", Palermos argues that it's necessary on certain robust forms of virtue reliabilism that we come to view these artifacts as actually constitutive of the cognitive processes that produce the beliefs at issue.
} 
distributed in ways I'll clarify. I then argue, lastly, in section three, that the beliefproducing process that Plantinga conceives as engendering faith is moreover a good candidate for an extended cognitive process. As we'll see this amounts to showing that there's no good reason for thinking that this belief-producing process cannot be cognitively integrated within one's cognitive character. I'll then summarize and conclude.

\section{VIRTUE EPISTEMOLOGY AND PLANTINGIANISM ABOUT FAITH}

\subsection{Virtue Epistemology}

To start with, notice that you don't necessarily know that $p$ if you truly believe that $p$ on account of a reliable belief-forming process. ${ }^{4}$ At least this is what virtue reliabilists say against more austere forms of process reliabilism in epistemology.

For example, the thermostat on the wall might reliably indicate the temperature of your room, such that not easily do you consult the thermostat and thereby form a false belief about the ambient temperature. But while consulting the thermostat to determine the temperature might be a reliable belief-forming process in this way, that might not be for reasons you'd expect. For suppose that the thermostat is broken, so that it randomly reports fluctuating temperatures throughout the day. As it happens, though, you have a hidden friend who is controlling the temperature of your room, always adjusting it so as to fit the reading on the thermostat. If you were to form a true belief by consulting the thermostat in this case, it seems that you wouldn't know what you thus believe, despite your believing what you do on the basis of a reliable belief-forming process. Plausibly, that's because your getting it right on this occasion isn't owing to an exercise of your cognitive abilities, so as to manifest your epistemic agency. Rather your getting it right is entirely to do with the help of your mysterious friend. ${ }^{5}$

\footnotetext{
${ }^{4}$ Never mind for the moment about how we're to specify or individuate these belief-forming processes. This is the well-known 'generality' problem for reliabilist views on knowledge, which we haven't time to address here.

${ }^{5}$ This case is otherwise known as the 'Temp' case. See Pritchard (2010a) (2010b).
} 
It's in light of cases like these that virtue reliabilists recommend an ability constraint on knowledge on top of a mere process reliability requirement. It's not enough for knowledge that you truly believe something as a result of just any reliable belief-forming process. Rather that process must be linked to a display of some ability on your part to get things right on the matter in question, so that when you believe correctly as a result of this process you're creditable for the cognitive success.

It might be tempting to think that the reason why you don't know in the thermostat case is that while you're reliable about the temperature this has little to nothing to do with any reliable belief-forming process located in the head-there's no reliable neural belief forming process at play in the causal-explanation why you're as reliable as you are about the temperature. You might think that so long as the reliability of a belief-producing process is located in the head in this way then any true belief it produces would satisfy the ability constraint.

This is wrong, however. For not all reliable belief-forming processes whose reliability is 'internal' in this way are such that were you to truly believe something on their basis, we'd credit your success to your epistemic agency. That is to say that not all executions of a reliable neural belief-forming process count as a display of some cognitive ability of the sort at issue here (i.e. an ability whose exercise can underwrite knowledge).

For example, you might find yourself (truly) believing a whole host of things for reasons you don't understand. That might be because you've suffered a brain lesion that, as it happens, reliably produces true beliefs on these subjects. But although this looks to be an 'internally' reliable belief-forming process it doesn't amount to a cognitive ability on your part, at least not of the sort of interest here. That's because we wouldn't credit you for getting right the things you believe on the basis of this unusual neural beliefproducing process, consisting as it does in clear cognitive malfunction. ${ }^{6}$

The moral seems to be that you can't know something unless you believe it on the basis of a reliable belief forming process, such that your getting it right on the basis of that process is properly creditable to your cognitive agency, where it isn't sufficient for these purposes that the reliability of the belief-producing process at issue be 'internal'

\footnotetext{
${ }^{6}$ The brain lesion case is taken from Plantinga (1993).
} 
or in the head of the subject. But neither does it seem to be necessary, however, as we'll come to find below.

\subsection{Plantingianism about Faith}

Unfortunately for the Plantingian virtue religious epistemologist, the ability constraint on knowledge seems to problematize knowledge that might be produced on the basis of faith. I'll now proceed to show more specifically why that's the case.

First note that on Plantinga's view believing something on the basis of faith is a means of knowing religious subject matter. He writes that $(2000$, p. 256, 206) that "faith is not to be contrasted with knowledge (...)", but rather faith is "seeing the truth of the central Christian affirmations." It's only by an exercise of faith that one knows, for example, that God is in Christ Jesus reconciling the world to Himself. Otherwise, you might know, for example, that it says this in Christian scripture, or perhaps even that this is something you should believe (if you identify with the Christian tradition). But the claim here is that absent faith you can't believe that it's true in the manner required for knowing it.

Note secondly, however, that, as Plantinga (2000, p. 245) also writes: faith-based beliefs "don't come just by way of the normal operation of our natural faculties-they are a supernatural gift." After all, as he says, faith is a "belief producing process" that "consists in direct divine activity (my emphasis)" (p. 246). More exactly, Plantinga thinks that faith-based belief (and knowledge) is a product of a "three-tired" (p. 244) beliefproducing process, consisting of the Bible, the activity of the Holy Spirit, and a resulting doxastic state. ${ }^{7}$ This is meant to be the belief-producing process that God organized in order to secure among human beings true beliefs about Himself. In the paradigmatic case, as a subject habitually engages in reading the Scriptures, the text and the Holy Spirit conspire to produce true beliefs in the subject.

\footnotetext{
${ }^{7}$ Plantinga himself alternates between using 'faith' to refer to the whole 'three-tiered' process responsible for producing belief in propositions concerning the central Christian story, and using it to refer only to the third element of this process: the doxastic state itself. We shouldn't lose sight of this when reading Plantinga, although I don't expect this to ambiguity confuse any of the discussion to follow. (We might in addition recognize a third sense of 'faith', as when one talks of the 'items of faith', which are supposedly propositions, not beliefs or processes). Thanks to a referee for encouraging me to flag this issue.
} 
Whatever the ultimate merits of these theological claims about faith-based belief, for our purposes we can boil them down to two, and call their conjunction Plantingianism about faith-based knowledge:

(I) Faith: Faith is the entire three-tiered process of (1) one's coming to believe some claim regarding God's great scheme for human salvation (2) as the result of the work of the Holy Spirit making one to believe (3) what she finds in Scripture.

(II) Faith Alone: Only by believing as a result of the process above can one properly know some claim regarding God's great scheme for human salvation. ${ }^{8,9}$

But now the worry for the Plantingian virtue religious epistemologist is that it hardly seems to be owing to your epistemic agency that you believe something correctly when you believe it on the basis of faith. Rather it seems to have everything to do with the agency, or the activity, of the Holy Spirit—it looks to be an entirely divinely orchestrated event.

And so if the ability constraint on knowledge is correct then it's hardly clear how you know what you believe on the basis of faith as that's being conceived here. Or in other words: how is one to make sense of the idea that when you believe something truly on the basis of faith this can be put down to an exercise of your cognitive abilities such that your getting it right is largely due to your epistemic agency? This seems to force a choice between virtue reliabilism and Plantingianism about faith-based belief. Premise two of our argument looks initially compelling: cases of faith-based belief are not cases in which you form true beliefs on account of your cognitive abilities.

\footnotetext{
${ }^{8}$ Thanks to a referee for the journal for recommending this succinct formulation of Plantinga's views on this score in terms of these two theses.

${ }^{9}$ But is it really necessary for you to know of God's grand scheme for human salvation that you encounter truths about it in scripture? Will not one's hearing it suffice? That's probably right. If it is then the idea I'm motivating in this paper will most clearly apply to the kind of faith-based knowledge enjoyed by those who in any case glean very little from hearing the Scripture taught to them, but more from reading it. But it remains that even for those who know elements of the central Christian story by hearing them believe them a result of a work of the Holy Spirit, and so there's still motivation on this Plantingian view of the production of faith for conceiving faith-based knowledge as extended in the way I'll begin to outline shortly.
} 


\subsection{Stronger and Weaker Versions of the Ability Constraint}

But perhaps things are not as desperate as they first appear for the Plantingian virtue religious epistemologist. For it might be that if we get clearer about what the ability constraint on knowledge requires, we'll find that it doesn't demand anything that faithbased belief can't be seen to accommodate.

Perhaps it seems that cases of faith-based belief are not cases in which you form true beliefs on account of your cognitive abilities only because we're assuming a rather strong conception of that what amount to. Namely, we're assuming that in such cases you're meant to believe what you do such that your getting it right on the matter in question is primarily creditable to your cognitive agency. ${ }^{10}$ Now if this is the correct interpretation of the ability constraint then faith-based knowledge surely looks impossible. For it seems indisputable that when you get something right by believing it on the basis of faith this isn't primarily creditable to you, since it's most conspicuously owing to the supernatural intervention of divine agency. However, if there are independent reasons to think that this is too strong a construal of the ability constraint anyway, then perhaps there's a weaker version that's weak enough for a virtue-theoretic explanation of faith-based knowledge.

Indeed there do seem to be reasons to suggest that the ability constraint is too strong as interpreted above. Consider for example a standard case of testimonial-based knowledge. You come off the train in a foreign city and ask a seemingly reliable informant for directions to the museum. ${ }^{11}$ If they tell you that it's on Third Street, surely you can come to know this by trusting them. But surely that's not in part because your getting it right about the location of the museum is primarily creditable to your cognitive agency. Rather your hitting upon the truth in this regard seems primarily creditable to the epistemic agency of your informant. Nevertheless you come to know

\footnotetext{
${ }^{10}$ Pritchard (2010b) distinguishes between two readings on the ability constraint on knowledge: a strong reading that requires that one's cognitive success be primarily credible to one's cognitive agency, and a weaker reading that requires that it only be significantly credible. We'll make much of this distinction in what follows.

${ }^{11}$ Jennifer Lackey (2007) first introduced this sort of case. Duncan Pritchard (2010b) uses the case to make the point I make in what follows: that the strong reading of the ability constraint is too strong since it fails to legitimate knowledge gleaned from testimony.
} 
what you do, and this suggests that the current interpretation of the ability constraint on knowledge is too strong.

Perhaps we should say instead, then, that when you know that $p$ you must believe that $p$ on the basis of a reliable belief-producing process such that your getting it right is at least significantly creditable to you cognitive agency. This seems weak enough to permit knowledge on the basis of trusting the testimony of others. For surely when you believe what you do in these cases your getting it right is at least significantly creditable to your cognitive agency, if not primarily creditable. You did well enough not to ask directions of a rubbish bin, for instance, and were your informant to betray signs of untrustworthiness you'd do well enough to take notice, and suspend judgment about what they tell you.

But now the question is whether this weakened ability constraint is also weak enough for explaining how, in cases of putative faith-based knowledge, you get it right on the matter at issue on account of your cognitive abilities. Can some sense be made of the idea that when you truly believe that $p$ on the basis of faith, your believing truly is at least significantly creditable to your epistemic agency?

I'm not optimistic. In fact there seems to be an important dissimilarity between faith-based belief and testimonial-based belief that suggests that you might not even be significantly creditable for getting something right on the basis of faith. For at least when you know something on the basis of testimony you form your belief of your own accord in a way that's partly explained by, among other things, your actively monitoring your situation, including your being on the look-out for reasons to doubt either the sincerity or the competency of your informant. And so your believing something truly on the basis of testimony enjoins at least this much cognitive ability on your part. It seems entirely natural to say that you have an ability to believe truly of things by trusting the say-so of another.

By contrast, however, your believing something truly on the basis of faith is a thoroughly divinely orchestrated event, down to the very cause of your believing what you do. For it's not as though human beings are merely unable to discover the truth about religious subject matter on their own (for which reason the Scriptures were organized as a testimony). But neither are they so much as able to believe these truths on their own when confronted with them. Rather on the Plantingian model under 
consideration it's meant to be the job of the Holy Spirit to not merely facilitate, but actually to create belief on the part of the believing subject. In fact, it's no exaggeration to say that your believing something on the basis of faith is something the Holy Spirit does. ${ }^{12} 13$

As Plantinga (p. 254) writes: the Holy Spirit "gets us to accept" or "causes us to believe the great things of the gospel". He even goes so far as to say that the Holy Spirit "produces", even induces belief (p. 256). I daresay that I was never induced to believe anything by an informant, and that's in part because I clearly have an ability to form beliefs by trusting others. ${ }^{14}$ And I think the thing to say here is that it's far from obvious that I have a similar ability to form beliefs by trusting the words of Scripture, at least on the kind of Plantingianism under consideration.

I therefore conclude that even if paradigm cases of believing something truly on the basis of faith are cases of believing something truly on the basis of a reliable beliefforming process, they don't look to be cases in which you believe what you do on account of your cognitive abilities, and even on a weak construal of what that amounts to. That's because these don't seem to be cases in which your believing truly what you do is even significantly creditable to your cognitive agency, much less primarily creditable. And so I'm not optimistic about retreating to a weakened version of the ability constraint for disputing the idea that when you know something on the basis of faith you don't get it right on account of your cognitive abilities.

\footnotetext{
${ }^{12}$ In this connection Plantinga (ibid., 249) asks 'how does faith work?', and answers: 'The principle answer is that faith is a work - the main work, according to Calvin —of the Holy Spirit (...)”.

${ }^{13}$ Objection: if your believing some item of faith is something the Holy Spirit does, doesn't this entail that the Holy Spirit is somehow 'doing the believing' in the subject? That would be incredibly odd. After all, surely faith-based beliefs are qualities of the believing subject, not qualities of the Holy Spirit. In fact there's no real tension here. Compare a brain in a vat of nutrients whose being 'fed' beliefs by the neuroscientist. If you were this brain your believing that, say, there's something white and round before you would be a work of the neuroscientist, something she does, and this compatibly with the fact that the belief itself is an intrinsic quality of you (the neuroscientist isn't believing this for you in some sense).

${ }^{14}$ If you'll permit the reference to popular culture, this seems to look like how someone comes to believe something on the basis of a 'Jedi-mind trick', which is similarly something the Jedi does, with her characteristic wave of the hand. By contrast when you believe something on the basis of testimony your believing truly as you do isn't similarly something your informant does in this way (I take it).
} 


\section{FAITH AS EXTENDED KNOWLEDGE}

\subsection{Extended Cognitive Ability}

Even on a weakened conception of the 'ability constraint' on knowledge, we found that believing something truly on the basis of faith just doesn't look to be sufficiently creditable to the exercise of one's cognitive abilities. But it's time to come clean about the fact that up till now we've only had one's organismic cognitive abilities in viewthose realized by neural states beneath the skin and skull of the subject. But why think that one's cognitive abilities are all and only one's organismic cognitive abilities? Why not instead allow for cognitive abilities that are extended, or that are realized by cognitive processes driven along by extra-organismic elements?

I submit that in order to get around the argument for agnosticism from the ability constraint on knowledge the Plantingian virtue religious epistemologist should conceive of faith as a form of extended knowledge by virtue of its being produced by an extended cognitive ability. The idea is that people who know things on the basis of faith believe truly as they do on account of a cognitive ability of theirs that actually consists in the activity of the Holy Spirit in conjunction with the deliverances of Scripture. More exactly, the cognitive ability in question is at least a disposition on the part of the subject to execute, in the proper circumstances, a cognitive process whose proper parts include the Holy Spirit and Scripture. ${ }^{15}$

On its face this can seem a rather staggering claim. ${ }^{16}$ For you might think that cognitive processing is an entirely 'internal' matter in that it goes on entirely inside one's head. To insist rather that the belief-producing process responsible for faith-based belief actually constitutes a cognitive process seems in direct violation of a kind of 'internalism' about cognitive processing. For it suggests that the factors that actively drive cognition

\footnotetext{
${ }^{15}$ For our purposes there's no need to settle on a definition of cognitive abilities.

${ }^{16}$ Although this is not a claim that Plantinga seems to have any trouble making. He refers to the mechanism of faith as a "cognitive process" (2000, p. 243). The problem, however, is that he doesn't justify the use of this terminology. He doesn't explain how a belief-producing process containing external world objects and other persons as proper parts can amount to anything recognizably 'cognitive'. The present work can be seen as trying to fill the gap in this regard.
} 
along can include such blatantly 'external' things as a book and the agency of another person $!^{17}$

But actually this is by no means unprecedented. In fact not only is cognitive science already familiar with the idea that something like a book might constitute a cognitive process, but also with the idea that another person might do so as well. To use a phrase from Clark and Chalmers (1998, p.14), we're learning that when it comes to cognition there is nothing sacred about skull and skin.

Proponents of extended cognition in cognitive science, for example, hold that some cognitive processing involves the use of external artefacts and/or instruments in ways that suggest that these artefacts actually play a constitutive role in driving these processes along. And proponents of distributed cognition go further still, arguing that cognitive processing might depend constitutively in this way not only on external artefacts, but other persons as well. I'll present these two views in turn.

\subsection{Extended Cognition and Distributed Cognition}

To get a grip on the idea behind the thesis of extended cognition, consider what's become a stock case in this regard. ${ }^{18}$ Otto's biological or organismic memory is failing him. He notices this and so begins to carry with him a notebook in which he jots down the sort of information he would need throughout the course of an ordinary day- the sort of information you or I would simply store in our biological memories. And so when it comes time for you to meet Otto for dinner, while you might remember where you've planned to meet him by consulting your biological memory, Otto will 'remember' this by virtue of consulting what he's written down in his notebook. The claim is that since

\footnotetext{
${ }^{17}$ I should clear up an ambiguity inherit in our talk of 'cognitive processes'. On one interpretation, a cognitive process is any process that issues in some doxastic state. In this sense the belief producing process consisting of the Bible and the activity of the Holy Spirit is quite clearly a cognitive process, and we don't need any thesis about extended cognition to make sense of that. But there's another interpretation of 'cognitive process' which picks out what cognitive scientists are happy to consider a cognitive process, where cognitive processes here are more tightly associated with one's 'mental activity'. It's with respect to this interpretation of 'cognitive process' that the extended cognition thesis is a quite surprising and controversial idea.

${ }^{18}$ In their seminal paper on the topic Clark and Chalmers (1988) first introduced this case in order to motivate something much stronger than we're concerned to show here: viz., the idea that one's mental states could actually extend out into the artifacts we rely on in the relevant ways.
} 
there seems to be no functional difference with respect to how the two of you store and retrieve information we should think of Otto's notebook as actively driving the cognitive processes he employs in figuring out where to meet you for dinner. Andy Clark and David Chalmers (1998, p. 8) write that:

If, as we confront some task, part of the world functions as a process which, were it done in the head, we would have no hesitation in recognizing it as part of the cognitive process, then that part of the word is (so we claim) part of the cognitive process. Cognitive processes ain't (all) in the head!

And so what's suggested here is that when Otto arrives for dinner according to plan that is in part because he knew where and when to arrive by virtue of exercising a cognitive ability that's extended by virtue of containing the notebook as a proper part. Otto's knowledge is thus extended in this sense, since it's the product of an extended cognitive ability.

But this isn't the only way 'extended knowledge' might be generated. For such knowledge might also be produced on the basis of a cognitive process that isn't merely extended but (also) distributed: a cognitive process consisting not (or not only) of external material artefacts, but also other subjects or persons.

The idea that cognitive processes might be distributed in this way can be motivated in connection with our wanting to understand knowledge on the part of scientific research teams, for example, or else other forms of group knowledge that are distinctively social or collaborative in nature. The idea here is that if we can come to see the individuals of these research teams as collectively realizing a kind of sui generis cognitive process, the way is opened to conceiving of the members of these groups as forming something of a 'group agent'. And if we can conceive of research teams as group agents, then there's scope for understanding distinctively social knowledge of the sort at issue in terms of the conceptual resources furnished by more mainstream or agentfocused epistemology. ${ }^{19}$

\footnotetext{
${ }^{19}$ Orestis Palermos and Duncan Pritchard (2014) point this out.
} 
Alternatively, so-called transactive memory systems are thought to provide support for the idea that cognitive processes might actually be distributed among two or more agents. Consider a case that Wegner et al. (1985, p. 257) describe:

Suppose we are spending an evening with Rudy and Lulu, a couple married for several years. Lulu is in another room for the moment, and we happen to ask Rudy where they got that wonderful staffed Canadian goose on the mantle. He says "we were in British Columbia...," and then bellows, "Lulu! What was the name of that place we got the goose?" Lulu returns to the room to say that it was near Kelowna or Penticton-somewhere along lake Okanogan. Rudy says, "Yes, in that area with all the fruit stands." Lulu finally makes the identification: Peachland.

The idea here is supposed to be that neither Rudy not Lulu individually know that it was in Peachland where they bought the staffed Canadian goose. But they do know it collectively, or together, and that plausibly by virtue of constituting a distributed cognitive process or ability, whereby in cueing one another in the manner illustrated above they're together able to recall some bit of information.

\subsection{An Objection}

Now it might not have gone unnoticed that these two cases of putatively distributed cognition don't quite seem to illustrate what I'm recommending in connection with faith-based belief: viz., that one of a subject's cognitive processes can be a distributed cognitive process in the sense that it involves one or more subjects as proper parts. For while the research team case and the Rudy-Lulu case illustrate cognitive processes that might include other subjects as proper parts, these cognitive processes don't seem to belong to any one subject as one of their cognitive processes.

This is probably most clear in the research team case, since there the cognitive process at issue belongs not to any individual researcher, but to the collective as a kind of 'group agent'. But the claim at issue with respect to the cognitive process responsible for 
producing faith is not that it belongs to some group agent comprising the believing subject and the Holy Spirit. ${ }^{20}$

I should say however that matters aren't similarly so clear-cut concerning the Rudy-Lulu case. For consider someone who didn't like the idea of 'group agents' (perhaps they thought group agents were just too spooky a specimen). What's to prevent her from thinking all the same that the Rudy-Lulu case motivates a kind of 'externalism' about cognitive processing that goes beyond the idea that cognition is merely extended to external artefacts? For instance, what would preclude this person from thinking that Rudy enjoys a distributed cognitive process by virtue of its consisting of Lulu as a proper part, and that Lulu enjoys a distributed cognitive process by virtue of its consisting of Rudy as a proper part, and that no cognitive process involving both Rudy and Lulu belongs to some group agent comprised of both Rudy and Lulu? But if there's a weaker interpretation of this and similar cases that's available along these lines (one that needn't postulate 'group agents') then we do already have kinds of case that illustrate what I want to say about the cognitive process consisting of the activity of the Holy Spirit.

But the more important point is that in order to serve their purpose the 'research team' and 'Rudy-Lulu' cases needn't strictly illustrate the form of distributed cognition I'm trying to motivate on behalf of a religious believer. It's sufficient that they establish precedent for the general idea that cognitive processes might consist of other agents, never mind to 'whom' those cognitive processes belong. It seems that until the Plantingian virtue religious epistemologist is given some principled reason to think that a cognitive process cannot both belong to some one subject and be distributed, she should feel free to appeal to a process of this sort for making sense of faith-based knowledge. ${ }^{21}$

In light of the forgoing, then, it's hardly ad hoc for the Plantingian virtue religious epistemologist to claim that the cognitive ability at issue in producing faithbased knowledge actually consists of Scripture and the agency of the Holy Spirit. For the idea that the parts of a cognitive process might include an external artefact (like a book)

\footnotetext{
${ }^{20}$ Otherwise we'd have to abandon the idea that the faith-based knowledge that results is knowledge on the part of the human subject, and the central problem of the paper would lapse (to be replaced by other problems to be sure!).

${ }^{21}$ Thanks very much to an anonymous referee for inspiring this discussion.
} 
and/or another person is right in line with recent developments in cognitive science. But of course not just any 'external' belief-producing process qualifies as an extended or distributed cognitive process. There are standards here as anywhere else. What this boils down to is that the process must be appropriately cognitively integrated with the rest of one's cognitive character. And so it remains to determine whether the belief-producing process at issue in the production of faith-based belief plays well the role of an extended cognitive process: or, what amounts to the same thing, whether it can be seen to be appropriately cognitively integrated.

If the mechanism of faith can be seen to be cognitively integrated with the rest of a subject's stable capacities in the way required, then our virtue religious epistemologist is unencumbered to conceive of this process as realizing a cognitive ability on the part of a religious subject. I turn to consider this next.

\section{COGNITIVE INTEGRATION}

I claim that there's no obstacle to viewing the reliable belief-producing process at issue in cases of faith as an extended/distributed cognitive process, on any viable conception of the criteria for cognitive integration. To show this I'll evaluate the belief-producing process at issue in faith-based belief with respect to two different criteria on this score: the so-called 'glue and trust' criterion, and what I'll call the criterion of 'reciprocal interaction' stemming from dynamical systems theory.

\subsection{Glue and Trust}

Beginning with the 'glue and trust' criterion, we might follow Clark and Chalmers (1998, p. 17) in thinking that when determining whether a reliable-belief producing (/sustaining) process should count as an extended cognitive process "what is central is a high degree of trust, reliance, and accessibility." 22 First, the elements comprising a

\footnotetext{
${ }^{22}$ Clark and Chalmers (1998) are less concerned than we are with epistemological issues. And so the criteria they list in terms of trust, reliance, and accessibility are criteria strictly for determining whether some 'external' reliable belief producing process counts as a cognitive process, not a cognitive ability. Nevertheless, we're working on the assumption that an extended cognitive ability is at least a disposition to
} 
belief-producing process won't count as constituting an extended cognitive process unless they're trusted. For Clark and Chalmers this means that these features are phenomenologically transparent in a way: that a subject ordinarily automatically endorses the deliverances of the belief-producing process at issue, without any form of reflective scrutiny. Moreover, secondly, the subject should rely on the belief-producing process, where this means that when circumstances call for the sort of information supplied by the belief-producing process, the subject is liable to draw on that source ahead of any other. Lastly, the belief producing process should be accessible, or readily enough available to the subject. That is to say that the components of the process should be relevantly fixed or 'glued' to one's organism. ${ }^{23}$

To illustrate these criteria, recall Otto and his notebook. Plausibly the beliefproducing process consisting of Otto's notebook is a good candidate for an extended cognitive process on these criteria. When Otto consults his notebook for information he's previously endorsed and written down he isn't especially critical about what he reads. He doesn't consciously form beliefs about his notebook and it's reliability, for instance, when consulting it in this way, much as we don't form similar sorts of beliefs when consulting our biological memories. And so the belief-producing process consisting of Otto's notebook is transparent in this way. Moreover, Otto properly relies on the notebook since whenever he's in a situation in which he'd like to be able to retrieve information he's come across before, he first consults his notebook (he doesn't go about trying to find again the original source of information; he doesn't go about asking others for the information, etc.). Furthermore, it's stipulated that Otto takes his notebook with him everywhere he goes, and so it seems to be readily enough availableavailable as often as is required-as often as we'd like to have readily available our biological memories.

Does the belief-producing process consisting of Scripture and the activity of the Holy Spirit violate any of the 'glue and trust' requirements? Not obviously.

execute, in the right circumstances, some extended cognitive process. And so even if the criteria advanced by Clark and Chalmers in connection with cognitive processes are insufficient to underwrite cognitive processes that undergird knowledge-conducive cognitive abilities, these criteria still plausibly amount to necessary conditions for a belief-producing process to undergird a cognitive ability.

${ }^{23}$ These criteria linked to Clark and Chalmers are sometimes referred to as the 'glue and trust' criteria. 
First, this belief-producing process seems to be trusted by the subject in the relevant fashion. In the paradigmatic case, when a subject finds herself believing from having read in her Bible that, say, through Jesus' death there is redemption and the forgiveness of all wrongdoing (Col. 1:14), she's not especially critical of the reliability of the book, or of the activity of the Holy Spirit in producing in her the impression that it's true. These are transparent players in the relevant sense. It's simply part of the background that she's come to accept that the Holy Spirit is adequate to make her convinced of the things she reads in Scripture, and that the Scriptures are a reliable witness of all they speak to. What she takes herself to be receiving from these sources she swallows down uncritically as does Otto the information in his notebook.

Secondly, it isn't obvious that she doesn't rely on this process in the manner required by the 'glue and trust' criterion of extended cognition. It's not as though she's no more ready to consult the Bible as she is the Koran, the Hadith, or horoscopes on matters pertaining to her faith and religious practice. Furthermore, neither is she prepared to act on the basis of a religious claim unless she takes herself to have learned it on the basis of the belief-producing process at issue-at least not plausibly. To the extent that she doesn't, it seems that the belief-producing process comprising Scripture and the activity of the Holy Spirit is relied on the relevant way.

Thirdly, it seems that the components of the belief producing process at issue in faith are as readily available/accessible as required. Little needs to be said to motivate this claim in connection with the Holy Spirit. On standard Christian teaching the Holy Spirit actually resides within the regenerate individual, so that He's as readily accessible as any of one's more ordinary cognitive equipment. ${ }^{24}$ Obviously the Scriptures are not likewise accessible, at least not as accessible as Otto's notebook. The typical religious believer doesn't carry around with her and consult her Bible to the extent that Otto does with his notebook. ${ }^{25}$ And so you might worry that on the glue and trust criterion the

\footnotetext{
${ }^{24}$ For example: "Do you not know that you are God's temple, and that God's Spirit dwells in you?" (1 Corinthians 3:16).

${ }^{25}$ Might not Christians with smartphones fair better at satisfying the 'glue' condition on this score? Perhaps. If so then the maneuvering that follows might be unnecessary insofar as we have in view those particularly dependent on the Bible application on their phone. It will be necessary, however, for those not so dependent. Thanks to a referee for the journal for bringing this to my attention.
} 
belief-producing process undergirding faith-based belief is not a good candidate for an extended cognitive process after all.

But I don't think there's any deep problem here. Recall that on the 'glue and trust' criterion, in order to count as an extended cognitive process the elements of that process need only be readily enough available to the subject. ${ }^{26}$

In Otto's case this plausibly requires that his notebook be physically with him at all times, since the putative extended cognitive process comprising the notebook is meant to be substituting for an cognitive process one typically draws on nearly at all times_viz., biological memory.

But the belief-forming process whose elements consist of the Spirit and the Bible is not similarly substituting for any such cognitive process, one that a subject need nearly always being drawing on in the course of an ordinary day. So there's no obvious reason why the requirement that the elements of an extended cognitive process be readily enough available to one should require that one's Bible be as readily available as Otto's notebook. ${ }^{27}$

If defenders of the glue and trust criterion insist to the contrary that 'readily enough' requires that the elements of a putative extended cognitive process be as accessible as Otto's notebook is to him, then our response should be that this looks to exclude too much of what appear to be genuine cases of extended cognition (assuming there are any at all). Consider, for example, the ways in which one depends on pen and paper in working out a math problem, or the way in which one interacts with a microscope in conducting one's scientific research. ${ }^{28}$ These are plausibly prime examples

\footnotetext{
${ }^{26}$ Clark and Chalmers (1998, p. 11) write that "if the relevant capacities are generally there when they are required, this is coupling enough [for the purposes of constituting an extended cognitive process]."

${ }^{27}$ Alternatively, we may choose to drop the Scriptures out of the cognitive process altogether, so that the cognitive process responsible for producing the kind of faith-based extended knowledge at issue is only a distributed cognitive process (comprising the Holy Spirit) and not also an extended cognitive process (comprising a material artifact). I'm not unsympathetic to this. However in this paper my target is whether a virtue epistemology can be made consistent with Plantingianism about faith. And so for these purposes we'll assume that the belief-producing process at issue involves the Scriptures as well, even if ultimately the most sober pistology would have us reject this assumption. Thanks again to a referee for flagging this concern.

${ }^{28}$ Palermos (2011, p. 762) suggests that we should conceive of knowledge from the use of such instruments as a form of extended knowledge by virtue of one's exercising an extended cognitive ability consisting of states of the instrument itself.
} 
of an extended cognitive process in action, and yet one is not always with pen and paper, nor with a microscope.

And so I conclude that there isn't any good reason in light of the glue and trust criterion to think that the belief producing process responsible for producing faith can't constitute an extended cognitive process, and therefore an extended cognitive ability.

\subsection{Reciprocal Interaction}

What about the second of the two criteria for extended cognition I listed above: the criterion of 'reciprocal interaction'? Orestis Palermos (2016) writes that, on this criterion, "what is required in order to claim that two (or more) systems give rise to some extended or distributed process [...] is the existence of mutual (i.e. non-linear) relations - that arise out of feedback loops — between the contributing parts."

It's typical to refer to the watt governor to illustrate how this is supposed to work. In terms of dynamical systems theory the watt governor represents a coupled system, whose sub-components consist of the governor and the engine, engaging in certain reciprocal interactions with one another. As Palermos (ibid.) explains, the reason why these sub-components form to create a new coupled (or extended) system is that, first, unless we postulate the new coupled (or extended) system we haven't the means to explain certain emerging properties of the coupled system which can't be attributed to any of its component systems; and then second, because the governor and the engine interact with each other so intimately that these interactions cannot be feasibly described in terms of distinct inputs and outputs from one system to the other. That is to say that at no time is one component system in some state or behaving some way independently of the counterpart system's being in some state or behaving some way at the same time, and vice versa. As Palermos (2016) writes:

In the case of the governor-engine system again, one cannot account for all of the governor's long term behaviours without simultaneously taking into consideration the behaviour of the engine, and vice versa. [...] When the two of them are mutually interconnected—some of the governor's ongoing behaviour 
both determines and is_-simultaneously_-determined by the behaviour of the engine (and vice versa).”

In producing religious faith in a subject, does the belief-forming process at issue reciprocally interact with other operations belonging to the subject to count as coupled with the subject in the relevant way? If it cannot be seen that it does then at least by the lights of the reciprocal interaction criterion the mechanism of faith fails to count as a properly extended cognitive process, and so a fortiori an extended cognitive ability.

Interestingly, however, I think the processes that produce/sustain religious belief in an individual can be seen to cooperatively interact with other features/states of the subject herself in ways that suggest that together they play well the role of a coupled system, as that's been adumbrated above. In order to see this however we first need to get more specific about how the Holy Spirit makes one to believe the elements of God's scheme for human salvation when one encounters them in the Bible.

When you believe some religious proposition on the basis of faith, that's because the Holy Spirit "gets you to accept" or "causes you to believe" this. It's something the Holy Spirit does in you. That's what we said above, following Plantinga's lead. However, we left it ambiguous whether this was a basic or non-basic action on the part of Holy Spirit: whether your believing as you do is something He does directly or indirectly. On a more detailed version of how this works-a version Plantinga (ibid., p. 305) himself seems open to-your believing an item of faith is something the Holy Spirit does in you indirectly. More specifically, it's by making you to perceive the loveliness, attractiveness, or divine beauty of some religious proposition $p$ that the Spirit gets you to believe $p .{ }^{29}$ And, crucially, He does this in response to, or by drawing on, your affective dispositions: what capacity you have to love or take delight in the things of God.

For example, take a subject who's convinced on the basis of faith from their exposure to Scripture that through Jesus' death there is redemption and the forgiveness of all wrongdoing (Col. 1:14). On the more sophisticated model we're now looking at, your believing this is something the Holy Spirit does in you in response to your general

${ }^{29}$ When the Spirit gets you to believe that $p$ in this way, by first making you to perceive the divine loveliness or divine beauty of $p$, is the belief at issue acquired/sustained inferentially or non-inferentially? Plantinga (2000, p. 305) suggests that it's acquired non-inferentially, that the religious experience at issue occasions the formation of the belief. I'm inclined to think that this is right. 
affective condition to make to you perceive the divine beauty or loveliness of the fact that through Jesus' death there is redemption and the supreme forgiveness of all wrongdoing. ${ }^{30}$ The sense in which the Spirit draws from or responds to your affective capacities is that it's only insofar as you're disposed to delight in the things of God that the Holy Spirit is moved to make you to perceive this proposition to be lovely or beautiful. In this way, then, the production and sustenance of religious faith in an individual cannot be understood apart from the shape of a subject's wider affective profile-those of the subject's loves and hates vis-à-vis the things of God. ${ }^{31}$

So far though this is only enough to secure a linear relation between states/processes of the subject and the belief-forming process responsible for producing in her religious faith. If these systems are to be non-linearly or reciprocally related, then ideally one's religious faith would function in some capacity as feedback, informing the shape of one's religious affections (which in turn, according to the above account, informs the activity of the Holy Spirit in indirectly causing one to believe religious propositions by making them to perceive their beauty).

Interestingly, this seems to be just what happens when we consider the role one's faith-based beliefs play in one's religious practice. For certainly it's in light of the things one believes by faith that she acts in ways that, among other things, texture her religious affections: enlarging her love, adoration, or desire for the things of God. C.S. Lewis reflects something of the same sentiment in Mere Christianity when he writes:

Do not waste time bothering whether you "love" your neighbour; act as if you did. As soon as we do this we find one of the great secrets. When you are behaving as if you loved someone, you will presently come to love them (Book 3, Chapter 9).

\footnotetext{
${ }^{30}$ On the modal, your perceiving the divine beauty of some proposition 'occasions' your believing it in much the same way as your perceiving the features of a tree-ish thing occasions your believing that there's a tree.

${ }^{31}$ Objection: the account in question can't be right, since your perceiving some fact to be lovely or delightful isn't a good reason for thinking it true that the fact obtains. But even if it's true that this constitutes no good reason to believe the proposition in question, the objection assumes that in coming to believe something on the basis of faith one enjoys a kind of inferential justification on the basis of some reason. But plausibly faith-based beliefs are non-inferentially justified, in which case it's open to a Plantingian to argue that it's all part of the design plan, or part of what it is to function properly, that we'd come to believe religious truths non-inferentially on the basis of perceiving them to be attractive in various ways.
} 
It's one's religious faith that naturally spurs one on in her religious activity-in her habitual reading of the Scriptures, communicating with God through prayer, sharing about Jesus' story with others, and in general participating in the activities of the Church. And is it not by engaging in these religious activities that one naturally increases in their love or desire for the things of God?-desires and loves which, on the present account, the Holy Spirit then draws on in turn for sustaining or increasing one's religious faith.

And so it seems that religious faith isn't produced as a result of some 'external' belief-forming process operating in isolation from the rest of the subject's capacities and behaviours. Rather the production and maintenance of faith-based belief is the result of a complex two-way interaction between a subject and the mechanism comprising Scripture and the action of the Holy Spirit that is almost helical or dialectical in character. ${ }^{32}$ In the dynamic religious life the two are 'mutually interconnected' in the relevant way: the Holy Spirit is always both simultaneously determining and being determined by states of the subject who has a hand in shaping her affections by exercising her faith in religious practice. Likewise, the activity of the subject is always both simultaneously determining and being determined by the activity of the Holy Spirit, Who's always drawing on the subject's religious affections in producing/sustaining faith in her.

Therefore there seems to be no reason for denying that a subject interacts with the belief-producing process consisting in the activity of the Holy Spirit such that the latter is coupled with the subject in the relevant way, allowing for cognitive integration. Religious faith isn't produced/sustained in a subject apart from the mutual interaction of the subject and the Spirit in this way. The set up is such that you cannot understand the 'behaviours' of the Spirit in producing faith in one without simultaneously taking into account the behaviours of the subject who's all the time exercising that faith in religious practice, and vice versa. And this is just what we want to say of the two systems if one is

\footnotetext{
${ }^{32}$ Plantinga (2000, p. 303) strikes a similar chord when he writes this in connection with apprehending God's moral qualities: "The structure of [affections] and intellect here is perhaps a spiral, dialectical process: heightened affections enable us to see more of God's beauty and glory; being able to see more of God's beauty and glory and majesty in turn leads to heightened affections. There are certain things you wont know unless you love, have the right affections; there are certain affections you won't have without perceiving some of God's moral qualities (...)".
} 
to be properly conceived of as coupled to the other, according to dynamical systems

theory.

Therefore at least with respect to the criterion of 'cooperative interaction' there's nothing barring the belief-producing process at issue in the production of faith-based belief from counting as a bona fide extended cognitive process, and so an extended cognitive ability on the part of a subject.

I conclude that there are no obvious reasons for thinking that the beliefproducing process at issue in faith-based belief cannot constitute an extended and distributed cognitive process. For we've seen that there's no good reason to think that this process can't be cognitively integrated into one's cognitive character, on any viable conception of what that amounts to. ${ }^{33}$

\section{CONCLUSION}

At the beginning I set up a problem for the virtue religious epistemologist in the form of an argument for agnosticism about faith-based belief, at least as that's conceived along Plantingian lines. I said that in order to remain true to the ability constraint on knowledge the virtue theorist needed to motivate the idea that when you believe

\footnotetext{
${ }^{33}$ One might object that even if we allow that the Bible and the Holy Spirit comprise an extended cognitive ability by the lights of the 'glue and trust' and reciprocal interaction criterion, it still isn't clear that when you believe an item of faith on the basis of this cognitive ability your cognitive success is properly creditable to your cognitive agency. After all, it doesn't seem that it's you who exercises the relevant cognitive ability, but rather the Holy Spirit who exercises it. This objection assumes that in order for you to believe something truly in a way that's properly attributable to your cognitive agency not only do you have to believe it truly on account of your cognitive abilities, but on account of cognitive abilities who's exercise is additionally attributable to you in some sense. Call this the 'double-ownership' assumption. This assumption seems objectionable for at least two reasons. First, compare a similar objection with respect to visual perceptual knowledge. Your believing that there's a cup before you isn't attributable to your cognitive agency, since while it's on account of your cognitive abilities that you believe truly that there's a cup, you're not responsible for exercising the abilities in play. Rather Mother Nature has organized things such that, when you get a good look at a cup, sub-personal cognitive mechanisms over which you have no control go to work in producing the belief that there's a cup before you. But surely, even though the exercise of your abilities isn't creditable to your agency, you know that there's a cup before you, and believe truly to this effect on account of your cognitive agency. Secondly, the assumption seems to generate an unwelcome regress of abilities whose exercise is required for any true belief to be properly creditable to one's agency. For what else is it for an exercise of a cognitive ability to be attributable to you except that it be attributable to some ability you have to exercise that ability? And why stop there? Why shouldn't we then require that your exercise of this ability to exercise the first ability itself be attributable to you, that is, attributable to some third-order ability? Better for a virtue theorist to simply drop the double-ownership assumption concerning the attributability of a true belief to a subject's cognitive agency, in my view. Thanks to a referee for inspiring me to think these things through.
} 
something on the basis of faith you get it right on account of a cognitive ability, first impressions to the contrary.

We found that there was no accounting for this even on a weakened conception of the ability constraint, so long as we were restricted to a kind of 'internalism' about cognitive processing. This came down to the fact that, unlike when you believe something on the basis of ordinary testimony, your believing something on the basis of faith is a work of the Holy Spirit-it's something He does in you.

I proposed then that in order to explain faith-based knowledge the Plantingian virtue religious epistemologist should conceive of it as a form of extended knowledge by virtue of being produced by an 'externalist' cognitive ability that is extended by virtue of the contribution of Scripture, and distributed by virtue of the contribution of the Holy Spirit.

There's no good objection to this proposal by appealing to the criteria of extended cognitive processes. The elements comprising the belief-producing process at issue in faith-based belief pass any reasonable standard in this regard for comprising an extended cognitive process.

The result is that those who are given to believe the 'great things of the gospel' on the basis of faith aren't simply possessed of true religious beliefs independent of an exercise of a cognitive ability on their part. Rather faith is given to one in the sense that a religious subject is outfitted with a kind religious mindware ${ }^{34}$ by virtue of which their cognitive characters become extended in a distinctly religious way.

${ }^{34}$ To borrow a locution from Andy Clark (2001). 


\section{BIBLIOGRAPHY}

Clark, A. (2001). Mindware: An Introduction to the Philosophy of Cognitive Science, Oxford: Oxford University Press.

Clark, A., and Chalmers, D. (1998). "The Extended Mind”, Analysis, 58, 7-19.

Greco, J. (2010). Achieving Knowledge: A Virtue-Theoretic Account of Epistemic Normativity. Cambridge: Cambridge University Press.

Kallestrup, J., and Pritchard, D. (2016). 'Dispositional Robust Virtue Epistemology vs. Anti-Luck Virtue Epistemology', Performance Epistemology: Foundations and Applications, ed. M. Angel and F. Vargas, 31-48, Oxford: Oxford University Press.

Lackey, J. (2007). 'Why We Don't Deserve Credit for Everything We Know'. Synthese, $158,345-61$.

Lewis, C.S. (2001). Mere Christianity: a revised and Amplified Edition. San Francisco: Harper San Francisco.

Sosa, E. (2016). 'Epistemic Competence and Judgment', Performance Epistemology: Foundations and Applications, ed. M. Angel and F. Vargas, 19-29, Oxford: Oxford University Press.

Palermos, O. (2011). 'Belief-Forming Processes, Extended', The Review of Philosophy and Psychology, 2, 741-765.

. (2014a). 'Knowledge and Cognitive Integration', Synthese, 191, 1931-1951.

. (2014b). 'Loops, Constitution, and Cognitive Extension', Cognitive Systems Research 27 25-41.

, and Pritchard, D. (2016). 'The Distribution of Epistemic Agency', Social Epistemology and Epistemic Agency: De-Centralizing Epistemic Agency, ed. P. Reider, 109-126, Rowman and Littlefield.

Plantinga, A. (1993). Warrant: the Current Debate. New York: Oxford University Press. . (2000). Warranted Christian Belief. New York: Oxford University Press.

Pritchard, D., Millar, A., and Haddock, A. (2010a). The Nature and Value of Knowledge: Three Investigations, Oxford: Oxford University Press. 
. (2010b). 'Cognitive Ability and The Extended Cognition Thesis'. Synthese $175,133-151$.

Wegner, D., Giuliano, T., Hertel, P. (1985). 'Cognitive Interdependence in Close Relationships. Compatible and Incompatible Relationships, ed. W.J. Ickes, 253276, New York: Springer-Verlag. 